\title{
SIFAT KEMBANG-SUSUT DAN KADAR AIR KESEIMBANGAN BAMBU TALI (Gigantocbloa apus Kurtz) PADA BERBAGAI UMUR DAN TINGKAT KEKERINGAN
}

\author{
(Shringkage-Swelling Properties and Equilibrium Moisture Content \\ of Bambu Tali (Gigantochloa apus Kurtz) at Various Age and \\ Drying Level)
}

\author{
Oleh/By : \\ Efrida Basri ${ }^{1)}$ \& Saefudin ${ }^{2)}$
}

\begin{abstract}
The shrinkage-swelling of bamboo during drying process continues until bamboo reaching equilibrium moisture content (EMC) with its environtment. Therefore, the information of shrinkage-swelling properties and EMC for bamboo are important to maintain product quality. The experiment was carried out for 3, 4 and 5-year-old bamboo samples taken from the lower, middle and upper ends of bamboo stem. These samples were oven dried at $60^{\circ} \mathrm{C}$. Investigation of shrinkage-swelling properties and EMC was carried out at moisture content (MC) $0 \%, 6 \%$ and $12 \%$, respectively.

Results showed that the 4-year old bambu tali was physically harvestable and had stable dimension. Drying bambu tali to EMC $6 \%$ resulted in EMC of around $9 \%$.
\end{abstract}

Key word: Shrinkage-swelling, EMC, age, drying level, bamboo

\begin{abstract}
ABSTRAK
Proses kembang susut berlangsung selama kadar air bambu belum mencapai kadar air keseimbangan (KAK) dengan lingkungannya. Oleh karena itu pengetahuan tentang sifat kembang susut dan KAK penting diketahui untuk menjaga mutu produk. Penelitian dilakukan pada bambu tali (Gigantochloa apus Kurts) umur 3, 4 dan 5 tahun yang diambil dari bagian pangkal, tengah dan ujung batang. Pengeringan menggunakan metode oven pada suhu $\pm 60^{\circ} \mathrm{C}$. Perlakuan kadar air untuk pengujian sifat kembang susut dan KAK adalah $0 \%, 6 \%$ dan $12 \%$.

Hasil penelitian menunjukkan bahwa bambu tali umur 4 tahun secara fisik sudah masak tebang dan dimensinya relatif stabil. Pengeringan bambu tali sampai ke kadar air 6\% menghasilkan KAK pada level sekitar $9 \%$.
\end{abstract}

Kata kunci : Kembang-susut, KAK, umur, tingkat kekeringan, bambu

\footnotetext{
1) Peneliti pada Pusat Penelitian dan Pengembangan Hasil Hutan, Bogor

2) Peneliti pada Pusat Penelitian Biologi - LIPI, Bogor
} 


\section{PENDAHULUAN}

Saat ini, peranan bambu sebagai bahan substitusi kayu sudah banyak digunakan di berbagai negara. Selain dikagumi karena memiliki elastisitas dan kekuatan, bambu cocok untuk konstruksi seperti baja karena bentuknya yang menyerupai pipa atau dijadikan bahan konstruksi modern dengan teknik penyambungan (Kusuma, 2006). Bahkan bambu lamina dari China untuk produk lantai dijual dengan harga sekitar Rp 250.000/ $\mathrm{m}^{2}$ (Sulastiningsih, 2006).

Salah satu jenis bambu Indonesia yang potensinya cukup tinggi dan memiliki keunggulan sebagai bahan konstruksi (termasuk mebel) adalah bambu tali atau bambu apus (Gigantochloa apus Kurz). Bambu ini sudah lama dikenal, khususnya di pedesaan karena mudah diperoleh dan dengan harga yang terjangkau.

Bambu tali yang baru ditebang kadar airnya bisa mencapai 185\% (Basri dan Saefudin, 2004). Bila bambu mengering, baik secara alami maupun melalui proses pengeringan dimensinya akan menyusut. Penyusutan ini akan berakibat terhadap perubahan dimensi bambu, yang jika tidak dikendalikan akan menyebabkan penurunan mutu bambu tersebut. Menurut Liese (1985) dan Fangchun (2000), tingkat penyusutan pada bambu sejenis bergantung pada umur, posisi letak pada batang dan tingkat kekeringan bambu.

Selain dimensinya menyusut, dimensi bambu yang telah kering juga bisa mengembang jika menyerap air, yang besarnya bergantung pada kemampuannya menarik air dari lingkungan. Persentase pengembangan akan menurun dengan bertambahnya kerapatan atau berat jenis bambu dan tingkat kekeringan bambu (Sekhar and Rawat, 1964; Fangchun, 2000). Hasil penelitian pada jenis bambu Phyllostachys sp. di China menunjukkan bahwa selain penurunan sifat fisik, beberapa sifat mekanis bambu kering juga menjadi turun setelah kadar airnya naik di atas 10\% (Fangchun, 2000).

Dari uraian di atas menunjukan sifat kembang-susut sangat dipengaruhi oleh perubahan kadar air dan akan menjadi masalah terhadap mutu produk yang hendak diekspor ke negara yang berbeda iklim dengan Indonesia atau di antara wilayah Indonesia yang berbeda suhu dan kelembaban lingkungannya. Oleh karena itu, bahan baku bambu yang akan dijadikan produk harus dikeringkan hingga mencapai kadar air keseimbangan (KAK) dengan lingkungan dimana produk tersebut akan dipasang agar dimensinya tetap stabil. KAK untuk produk dari bahan berlignoselulosa seperti bambu dan kayu, yang akan ditempatkan dalam ruangan berpendingin (air conditioner) atau yang akan diekspor ke negara empat musim, berkisar antara 8 - 11\% (Desch, 1968 dalam Basri dan Rahmat, 2001).

Sehubungan dengan hal tersebut di atas, tujuan penelitian adalah untuk mengetahui pengaruh tingkat kekeringan bambu tali yang berbeda umur dan posisi letak pada batang terhadap KAK dan sifat kembang susutnya. Sebagai tahap awal pengamatan KAK dan pengembangan dimensi dilakukan pada suhu kamar $\left( \pm 24^{\circ} \mathrm{C}\right)$. 


\section{BAHAN DAN METODE}

Jenis bambu yang diteliti adalah bambu tali (Gigantochloa apus Kurz) umur 3,4 dan 5 tahun yang diambil di Cibinong, Bogor. Pengambilan contoh uji dilakukan di musim penghujan pada bagian pangkal (batas banir), tengah, dan ujung batang.

Contoh uji untuk setiap pengamatan dijadikan bilah dengan ukuran panjang $60 \mathrm{~mm}$ dan lebar $30 \mathrm{~mm}$. Hal ini dilakukan agar contoh uji dapat lebih cepat kering dan perubahan dimensi arah tebal yang dijadikan perlakuan dapat diukur. Perubahan arah dimensi panjang sangat kecil sehingga secara teknis diabaikan. Semua contoh uji ditimbang berat dan diukur dimensi tebalnya pada kondisi basah dan selanjutnya dibagi menjadi 3 kelompok untuk dikeringkan dalam oven pada suhu $\pm 60^{\circ} \mathrm{C}$, sesuai dengan suhu optimum yang diperoleh dari hasil percobaan penetapan bagan suhu. Tingkat kekeringan bambu untuk pengamatan adalah $0 \%, 6 \%$ dan $12 \%$, yang diperoleh dengan cara mengeringkan bambu basah hingga mencapai kadar air $0 \%, 6 \%$ dan 12\%. Untuk mendapatkan tingkat kekeringan bambu tali $0 \%$, contoh ujinya harus dikeringkan dalam oven pada suhu $101^{\circ} \mathrm{C}$ hingga beratnya konstan (berat kering tanur). Selanjutnya contoh uji diukur dimensi penyusutan tebalnya dan ditempatkan di ruang terbuka (di laboratorium Pengeringan P3HH Bogor) sampai mencapai KAK. KAK bambu kering bergantung pada perubahan suhu dan kelembaban harian di tempat penempatan. Contoh uji bambu tali dikatakan telah mencapai keadaan KAK apabila kadar airnya telah konstan, yaitu tidak lagi menarik atau mengeluarkan air ke lingkungannya. Selanjutnya contoh uji diukur pengembangan dimensi tebalnya. Penimbangan berat contoh uji menggunakan timbangan listrik dengan ketelitian sampai $0,01 \mathrm{~g}$ dan pengukuran dimensi menggunakan jangka sorong (dial caliper) dengan ketelitian sampai $0,05 \mathrm{~mm}$. Pada penelitian ini, pengukuran BJ bambu didasarkan pada berat kering oven terhadap volume bambu segar (basic density), sedangkan kadar air dalam persen merupakan nisbah berat air yang diperoleh dengan cara mengeringkan bambu dalam oven pada suhu $101-105^{\circ} \mathrm{C}$ sampai berat konstan.

Rancangan penelitian yang digunakan adalah rancangan tersarang (nested) dengan 3 faktor yaitu umur (3, 4, 5 tahun) sebagai kelompok utama dan letak ruas pada batang (pangkal, tengah, dan ujung) serta tingkat kekeringan (KA. 0\%,6\%,12\%) sebagai sub kelompok. Jumlah ulangan untuk setiap perlakuan 3 buah. Uji beda jarak antara nilai rata-rata hasil pengujian dilakukan menurut cara Duncan (Steel dan Torrie, 1993).

\section{HASIL DAN PEMBAHASAN}

Seluruh contoh uji mempunyai kadar air awal di atas titik jenuh serat ( $\mathrm{KA}>30 \%$ ), dimana dinding sel masih jenuh dengan air terikat. Dengan demikian seluruh contoh uji masih dalam ukuran alaminya, sehingga memenuhi syarat untuk digunakan dalam pengujian pengeringan.

Kadar air awal atau kadar air segar bambu tali asal Cibinong, bervariasi menurut umur, letak ruas pada batang dan tingkat kekeringan. Pada umur 3 dan 4 tahun, kadar air berkisar antara 65 - 161\% (Tabel 1). Dibandingkan dengan nilai kadar air bambu tali dari tempat tumbuh di Ciomas, Bogor, tampaknya kadar air bambu tali yang tumbuh di Cibinong lebih tinggi. Kadar air bambu tali pada umur 3 dan 4 tahun dari tempat tumbuh Ciomas, berkisar 
antara 62 - 110\% (Basri dan Saefudin, 2004). Tingginya kandungan air bambu tali asal tempat tumbuh Cibinong diduga karena penebangan dilakukan pada musim penghujan. Musim mempunyai pengaruh yang sangat besar terhadap kadar air segar bambu. Kadar air bambu yang ditebang pada musim penghujan bisa dua kali lebih tinggi dari pada kadar air bambu yang ditebang di musim kemarau (Liese, 1985). Lingkungan tumbuh bambu di daerah aliran sungai di lokasi Cibinong juga dapat mempengaruhi kadar air bambu sewaktu penebangan. Umur dan posisi letak pada batang juga mempengaruhi kadar air segar bambu. Semakin tua bambu dan semakin ke ujung letak batang, kadar airnya semakin rendah. Jaringan utama penyusun bambu adalah parenkim (40 - 60\%) yang melingkari berkas pembuluh (Liese, 1985; Fangchun, 2000; Anonim, 2001). Fungsi utama parenkim ini sebagai gudang nutrisi dan air. Persentase jaringan parenkim bambu akan menurun secara bertahap dari bagian pangkal ke bagian ujung dan makin berkurang dengan bertambahnya umur bambu (Anonim, 2001). Dengan berkurangnya air dalam bambu, kerapatan bambu akan naik (Tabel 1).

Tabel1. Nilai rata-rata kadar air awal, BJ, dan penyusutan dimensi tebal bambu tali pada 3 tingkat kekeringan

Table 1. Average value at initial moisture content, basic density and thickness shrinkage of bambutali at 3 drying levels

\begin{tabular}{|c|c|c|c|c|c|c|}
\hline \multirow{2}{*}{$\begin{array}{l}\text { Umur, } \\
\text { tahun } \\
\text { (Age, year) }\end{array}$} & \multirow{2}{*}{$\begin{array}{l}\text { Bagian batang } \\
\text { (Part of bamboo } \\
\text { stem) }\end{array}$} & \multirow{2}{*}{$\begin{array}{l}\text { Kadar air awal } \\
\text { rata-rata } \\
\text { (Average initial } \\
\text { MC), \% }\end{array}$} & \multirow[t]{2}{*}{$\begin{array}{c}\text { Berat jenis } \\
(\text { Basic density })^{1}\end{array}$} & \multicolumn{3}{|c|}{$\begin{array}{l}\text { Penyusutan arah tebal pada } 3 \\
\text { tingkat kekeringan (Thickness } \\
\text { shrinkage at } 3 \text { drying levels), \% }\end{array}$} \\
\hline & & & & $0 \%$ & $6 \%$ & $12 \%$ \\
\hline \multirow[t]{3}{*}{3} & $\mathrm{P}$ & 161 & 0,62 & 16,0 & 12,5 & 8,0 \\
\hline & $\mathrm{T}$ & 122 & 0,65 & 14,0 & 9,7 & 6,5 \\
\hline & $\mathrm{U}$ & 100 & 0,68 & 12,0 & 7,9 & 5,0 \\
\hline \multirow[t]{3}{*}{4} & $\mathrm{P}$ & 100 & 0,69 & 13,0 & 7,7 & 4,8 \\
\hline & $\mathrm{T}$ & 95 & 0,70 & 10,5 & 7,5 & 4,3 \\
\hline & $\mathrm{U}$ & 82 & 0,72 & 9,0 & 7,0 & 3,5 \\
\hline \multirow[t]{3}{*}{5} & $\mathrm{P}$ & 86 & 0,72 & 11,0 & 7,1 & 3,5 \\
\hline & $\mathrm{T}$ & 76 & 0,74 & 8,5 & 6,0 & 3,1 \\
\hline & $\mathrm{U}$ & 65 & 0,76 & 7,5 & 5,0 & 2,9 \\
\hline
\end{tabular}

Keterangan (Remarks): ${ }^{11}$ Didasarkan pada berat kering oven (Based on oven dry weight); $\mathrm{P}=$ pangkal (bottom); $\mathrm{T}=$ tengah (middle); $\mathrm{U}=\operatorname{ujung}($ top $)$

Data pada Tabel 1, menunjukkan adanya pengaruh nyata dari umur, letak ruas pada batang dan tingkat kekeringan terhadap penyusutan bambu. Semakin rendah tingkat kekeringan bambu semakin besar penyusutannya. Penyebab utama penyusutan adalah jaringan serat dalam berkas pembuluh bambu kehilangan air. Sebagai akibat, penyusutan makin tinggi dengan banyaknya air yang dikeluarkan dari dalam berkas pembuluh atau tingkat kekeringannya rendah. Dengan berkurangnya air, jaringan sel dan serat pada bambu akan menyatu/kokoh sehingga kekuatannya meningkat (Fangchun, 2000). Menurut Liese (1985), penyusutan pada bambu dimulai secara simultan dengan berkurangnya kadar air, namun tidak 
berlangsung terus menerus. Setelah mencapai kadar air 40\%, penyusutan akan berhenti dan mulai lagi ketika kadar air sudah mendekati titik jenuh serat. Hasil penelitian pada jenis Phyllostachys pubescens umur 4 tahun menunjukkan koefisien penyusutannya berubah-ubah sangat nyata ketika pengeringan dilakukan pada kadar air di bawah 25\% (KA. titik jenuh serat), sedangkan terhadap kadar air di atas 25\%, perubahannya tidak nyata (Anonim, 2001). Hasil penelitian di Cina pada P. bambusoid umur 4 tahun menunjukkan nilai penyusutan arah tebal dari kadar air segar ke kering udara (KA 12\%) adalah sekitar 4,5\% (Fangchun, 2000). Semakin rendah kadar air bambu semakin besar penyusutannya.

Sebagaimana halnya penyusutan, penyerapan air dari bambu yang telah kering juga dipengaruhi oleh umur, letak ruas pada batang, dan tingkat kekeringan bambu (Tabel 2). Laju penyerapan atau kapasitas air yang diserap oleh bambu kering untuk mencapai KAK dengan lingkungannya juga dipengaruhi tingkat kekeringannya (Tabel 3).

Tabel2. Nilai rata-rata BJ dan pengembangan dimensi tebal bambu tali dari 3 tingkat kekeringan

Table 2. Average value at basic density and thickness swelling of bambu tali at 3 dryinglevels

\begin{tabular}{|c|c|c|c|c|c|}
\hline \multirow{2}{*}{$\begin{array}{c}\text { Umur, tahun } \\
\text { (Age, year) }\end{array}$} & \multirow{2}{*}{$\begin{array}{c}\text { Bagian batang } \\
\text { (Part of bamboo }\end{array}$} & $\begin{array}{c}\text { Berat jenis } \\
\text { (Basic } \\
\text { stem) }\end{array}$ & \multicolumn{2}{|c|}{$\begin{array}{c}\text { Pengembangan arah tebal dari 3 tingkat } \\
\text { kekeringan (Thickness swelling from 3 drying } \\
\text { levels) } \%\end{array}$} \\
\cline { 4 - 6 } & $\mathrm{P}$ & 0,62 & $0 \%$ & $6 \%$ & $12 \%$ \\
\hline 3 & $\mathrm{~T}$ & 0,65 & 3,6 & 4,6 & 5,8 \\
& $\mathrm{U}$ & 0,69 & 3,1 & 4,2 & 5,2 \\
& $\mathrm{P}$ & 0,68 & 3,1 & 3,8 & 4,4 \\
\hline 4 & $\mathrm{~T}$ & 0,70 & 2,9 & 3,8 & 4,3 \\
& $\mathrm{U}$ & 0,73 & 2,5 & 3,3 & 4,0 \\
& $\mathrm{P}$ & 0,71 & 2,5 & 3,4 & 3,0 \\
\hline 5 & $\mathrm{~T}$ & 0,74 & 2,2 & 3,1 & 2,5 \\
& $\mathrm{U}$ & 0,76 & 2,0 & 2,9 & 2,2 \\
\hline
\end{tabular}

Keterangan (Remarks) : ${ }^{1)}$ Didasarkan pada berat kering oven (Based on oven dry weight); P = pangkal (bottom); $\mathrm{T}=$ tengah (middle); $\mathrm{U}=$ ujung (top) 
Tabel3. Nilai rata-rata BJ dan KAK bambu tali pada 3 tingkat kekeringan Table 3. Average value at basic density and EMC of bambu tali at 3 drying levels

\begin{tabular}{|c|c|c|c|c|c|}
\hline \multirow{2}{*}{$\begin{array}{c}\text { Umur, tahun } \\
\text { (Age, year) }\end{array}$} & $\begin{array}{c}\text { Bagian batang } \\
\text { (Part of bamboo stem) }\end{array}$ & $\begin{array}{c}\text { Berat jenis } \\
\text { (Basic density) }^{1}\end{array}$ & \multicolumn{3}{|c|}{$\begin{array}{c}\text { KAK pada } 3 \text { tingkat kekeringan } \\
(\text { EMC at 3 drying levels), \% }\end{array}$} \\
\cline { 3 - 5 } & & 0,62 & 5,0 & $6 \%$ & $12 \%$ \\
\hline 3 & $\mathrm{P}$ & 0,65 & 5,0 & 9,3 & 16,9 \\
& $\mathrm{~T}$ & 0,69 & 4,8 & 9,0 & 16,6 \\
4 & $\mathrm{U}$ & 0,68 & 5,0 & 8,9 & 16,5 \\
& $\mathrm{P}$ & 0,70 & 4,6 & 8,7 & 16,3 \\
& $\mathrm{~T}$ & 0,73 & 4,4 & 8,5 & 16,3 \\
& $\mathrm{U}$ & 0,71 & 4,4 & 8,6 & 16,0 \\
& $\mathrm{P}$ & 0,74 & 4,0 & 8,5 & 15,8 \\
& $\mathrm{~T}$ & 0,76 & 3,6 & 8,5 & 15,8 \\
\hline
\end{tabular}

Keterangan (Remarks) : Didasarkan pada berat kering oven (Based on oven dry weight); $\mathrm{P}=$ pangkal (bottom); $\mathrm{T}=$ tengah (middle); $\mathrm{U}=\operatorname{ujung}($ to $p)$

Seperti halnya kayu, bambu juga bersifat histeristis yaitu lebih mudah mengeluarkan air dari pada menyerapnya, terutama bila dikeringkan dengan suhu tinggi atau tingkat kekeringannya sangat rendah. Hal ini ditunjukan dari percobaan penelitian terhadap 10 jenis bambu di Cina (Fangchun, 2000) yang memperoleh hasil bambu yang dikeringkan sampai kering tanur (KA 0\%) memiliki kecepatan pengembangan dan pengembangan dimensi lebih rendah dibandingkan dengan bambu yang dikeringkan sampai kadar air kering udara (KA $\pm 12 \%$ ). Namun semua peneliti sepakat bahwa mengeringkan bambu sampai ke kering tanur malah dapat menurunkan kualitasnya karena bambu gampang pecah dan menjadi rapuh. Selanjutnya dikatakan bahwa kadar air yang memungkinkan untuk bisa mempertahankan mutu bambu adalah sekitar 5 - 10\%. Penyerapan air di atas 10\% sudah memungkinkan terjadinya penurunan kekuatan tekan sejajar serat bambu (Fangchun, 2000). Akan tetapi hasil penelitian yang lain (Anonim, 2001), memperoleh bahwa meskipun absorbsi kadar air sangat erat hubungannya dengan tingkat kekeringan bambu dan berpengaruh nyata terhadap sifat fisik bambu, namun terhadap beberapa sifat mekanis bambu, seperti kekuatan tarik secara transversal (transverse tensile strength) dan lentur statis pada arah tangensial (tangential static bending) tidak begitu nyata, sekalipun penyerapan airnya sudah mencapai titik jenuh serat (KA. $\pm 25 \%$ ). Hal ini karena letak jaringan pembuluh bambu pada arah vertikal sehingga penyusutan dan pengembangan hampir tidak memiliki pengaruh terhadap tekanan pada arah radial/tebal bambu. Salah satu cara untuk mempercepat pengeringan dan mengurangi daya serap bambu terhadap air, adalah merendamnya dalam air sebelum dikeringkan (Liese, 1985). Dengan demikian zat-zat ekstraktif dari bambu yang peka terhadap air akan larut.

Hasil uji sidik ragam (Lampiran 1) menunjukkan bahwa umur, letak ruas pada batang dan tingkat kekeringan berpengaruh sangat nyata terhadap penyusutan, pengembangan dimensi tebal dan KAK bambu tali. Hasil uji lanjutan (Lampiran 2) menunjukan bahwa pada 
tingkat kekeringan $0 \%, 6 \%$ dan 12\%, antara umur 3 dan 5 tahun berpengaruh nyata terhadap sifat kembang, susut dan KAK (kecuali pada tingkat kekeringan $0 \%$ ) bambu tali, sedangkan umur antara 3 dan 4 tahun atau 4 dan 5 tahun secara statistik tidak nyata pengaruhnya. Untuk tingkat kekeringan $0 \%$, KAK tidak berbeda nyata pada semua umur. Demikian pula hasil uji lanjutan yang tercantum dalam Lampiran 3 dan 4, menunjukan bahwa sifat kembang dan susut bambu tali pada tingkat kekeringan $0 \%, 6 \%$ dan $12 \%$ berpengaruh sangat nyata hanya pada bagian pangkal dan ujung batang, sedangkan antara pangkal dan bagian tengah atau tengah dan bagian ujung batang bambu tidak nyata pengaruhnya. Pengaruh tingkat kekeringan terhadap perubahan KAK bambu tali secara statistik hanya pada perlakuan $0 \%$ dan $6 \%$ dari batang yang letaknya di bagian pangkal dan di bagian ujung. Adapun pada tingkat kekeringan $12 \%$, KAK pada semua bagian batang relatif tidak berbeda.

Dari uraian di atas, menunjukkan peruntukan bambu tali sebagai bahan baku pertukangan (mebel dan komponen struktural) sebaiknya sudah dilakukan pada umur 4 tahun karena dari sifat kembang susutnya tidak begitu berbeda dengan bambu umur 5 tahun. Untuk mendapatkan kadar air keseimbangan produk mebel yang sesuai peruntukannya dalam ruangan berpendingin atau untuk ekspor, sebaiknya bahan baku bambu dikeringkan hingga ke kadar air 6-10\%. Hal ini sangat erat kaitannya dengan mutu produk (Fangchun, 2000).

\section{KESIMPULAN DAN SARAN}

\section{A. Kesimpulan}

1. Terdapat hubungan yang erat antara umur, ketinggian batang dan tingkat kekeringan terhadap sifat kembang, susut dan kadar air keseimbangan bambu tali.

2. Pada tingkat kekeringan yang sama, makin tua bambu tali dan makin ke ujung letaknya persentase penyusutan dan pengembangannya makin rendah. Namun secara statistik perbedaan ini hanya nyata pada umur antara 3 dan 5 tahun yang terdapat di bagian pangkal dan ujung batang. Hal ini menunjukkan bahwa pada umur 4 tahun secara fisik bambu tali sudah masak tebang.

3. Tingkat kekeringan $6 \%$ sudah mendapatkan kadar air keseimbangan bambu tali pada level 9\%. Produk bambu pada kadar air tersebut sudah memenuhi standar persyaratan pemakaian dalam ruang berpendingin (air conditioner) atau untuk tujuan ekspor ke negara empat musim.

\section{B. Saran}

Potensi bambu di Indonesia, khususnya bambu tali cukup tinggi dan kelak bisa menjadi bahan substitusi kayu pertukangan. Namun, penelitian tentang sifat-sifat bambu tersebut masih sangat terbatas. Oleh karena itu disarankan perlu diperbanyak penelitian dasar terhadap jenis bambu tali dan jenis lainnya yang belum banyak dimanfaatkan, terutama mengenai sifat anatomi, fisis dan mekanis yang mendukung teknologi pengolahan. 


\section{DAFTAR PUSTAKA}

Anonim. 2001. Cultivation and integrated utilization on bamboo in China: Structure and properties of bamboo timber. China National Bamboo Research Center.Hangzhou, P.R. China. pp. $56-72$.

Basri, E. dan Saefudin. 2004. Pengaruh umur dan posisi letak ruas pada batang terhadap sifat pengeringan tiga jenis bambu. Jurnal Penelitian Hasil Hutan Vol. 22 (3): 123-134. Pusat Litbang Teknologi Hasil Hutan, Bogor.

Basri, E. \& Rahmat. 2001. Pembuatan kilang pengeringan kayu kombinasi energi surya dan tungku. Petunjuk Teknis Pusat Penelitian dan Pengembangan Teknologi Hasil Hutan. Bogor.

Kusuma, B.W. 2006. Mengangkat gengsi bambu dalam arsitektur modern. Harian Kompas terbitan 23 April 2006. PT Gramedia. Jakarta.

Fangchun, Z. 2000. Selected works of bamboo research (translate Chinese into English by Chen Xinfang). The Bamboo Research Editorial Committee. Nanjing Forestry University, Nanjing China. Chapter XII-XIV: 95-125.

Liese, W. 1985. Anatomy and properties of bamboo. Proceeding of the International Bamboo Workshop Oct. 6 - 14, 1985. Hangzhou, People's Republic of China. pp. 196208.

Sekhar, A.C. and M.S. Rawat. 1964. Some studies on the shrinkage of Bambusa nutans. Dehra Dun. Indian Forest 91: 182-188.

Steel, R.G.D. \& J.H. Torrie. 1993. Prinsip dan prosedur statistik. Terjemahan. PT Gramedia Pustaka Utama, Jakarta.

Sulastiningsih, IGM. 2006. Pembuatan produk bambu lamina. Wawancara di Radio Pertanian Ciawi, Bogor tanggal 24 April, 2006. 
Lampiran 1. Sidik ragam penyusutan, pengembangan tebal dan KAK bambu tali Appendix 1. Analysis of variance thicknes shrinkages, swelling and EMC of bamboo tali

\begin{tabular}{|c|c|c|c|c|c|}
\hline $\begin{array}{l}\text { Faktor } \\
\text { (Factor) }\end{array}$ & $\begin{array}{c}\text { Sumber keragaman } \\
\text { (Source) }\end{array}$ & $\begin{array}{l}\mathrm{Db} \\
(\mathrm{df})\end{array}$ & $\frac{\mathrm{JK}}{(\mathrm{SS})}$ & $\begin{array}{l}\mathrm{JKT} \\
\text { (MS) }\end{array}$ & F hit \\
\hline $\begin{array}{l}1 \\
2 \\
3\end{array}$ & A Umur $(A g e)$ & 2 & $\begin{array}{l}27,764 \\
26,141 \\
36,086\end{array}$ & $\begin{array}{l}13,882 \\
13,071 \\
18,047\end{array}$ & $\begin{array}{l}33,776^{\text {** }} \\
19,393^{* *} \\
69,145^{\text {** }}\end{array}$ \\
\hline $\begin{array}{l}1 \\
2 \\
3\end{array}$ & B/A Tempat (Position)/A & 6 & $\begin{array}{l}21,551 \\
44,744 \\
26,046\end{array}$ & $\begin{array}{l}3,500 \\
7,457 \\
4,341\end{array}$ & $\begin{array}{c}8,516^{* *} \\
11,064^{* *} \\
16,632^{* *}\end{array}$ \\
\hline $\begin{array}{l}1 \\
2 \\
3\end{array}$ & $\begin{array}{l}\text { C/B/A T. kekeringan } \\
\text { (Drying leveX/B/A }\end{array}$ & 18 & $\begin{array}{c}157,77 \\
57,356 \\
104,760\end{array}$ & $\begin{array}{l}8,765 \\
3,186 \\
5,820\end{array}$ & $\begin{array}{r}21,326^{* *} \\
4,727^{* *} \\
22,299^{* *}\end{array}$ \\
\hline $\begin{array}{l}1 \\
2 \\
3\end{array}$ & Galat (Error) & 54 & $\begin{array}{l}22,204 \\
36,434 \\
14,092\end{array}$ & $\begin{array}{l}0,411 \\
0,674 \\
0,261\end{array}$ & \\
\hline & Jumlah (Total) & 80 & & & \\
\hline
\end{tabular}

Keterangan (Remarks) : 1 = Penyusutan (Shrinkage), 2 = Pengembangan (Swelling), 3 = KAK (EMC)

Lampiran 2. Uji beda nyata $\left(\mathrm{BNT}_{0,05}\right)$ terhadap rata-rata penyusutan, pengembangan dan KAK pada umuryang berbeda

Appendix 2. Significant difference's range test $\left(B N T_{0,05}\right)$ to the average thickness shringkage, swelling and EMC on difference age

\begin{tabular}{|c|c|c|c|c|c|c|c|c|c|}
\hline \multirow{2}{*}{$\begin{array}{c}\text { Umur, } \\
\text { tahun } \\
(\text { Age } \\
\text { year })\end{array}$} & \multicolumn{3}{|c|}{$\begin{array}{c}\text { Penyusutan } \\
\text { (Shrinkage) } \%\end{array}$} & \multicolumn{3}{c|}{$\begin{array}{c}\text { Pengembangan } \\
\text { (Swelling), } \%\end{array}$} & \multicolumn{3}{c|}{ KAK (EMC.), \% } \\
\cline { 2 - 10 } & $0 \%$ & $6 \%$ & $12 \%$ & $0 \%$ & $6 \%$ & $12 \%$ & $0 \%$ & $6 \%$ & $12 \%$ \\
\hline 3 & $14,03 \mathrm{a}$ & $10,03 \mathrm{a}$ & $6,33 \mathrm{a}$ & $3,33 \mathrm{a}$ & $4,20 \mathrm{a}$ & $5,13 \mathrm{a}$ & $4,93 \mathrm{a}$ & $9,67 \mathrm{a}$ & $16,67 \mathrm{a}$ \\
4 & $10,03 \mathrm{~b}$ & $7,90 \mathrm{ab}$ & $4,00 \mathrm{~b}$ & $2,83 \mathrm{ab}$ & $3,53 \mathrm{a}$ & $3,77 \mathrm{ab}$ & $4,67 \mathrm{a}$ & $8,71 \mathrm{ab}$ & $16,37 \mathrm{ab}$ \\
5 & $9,83 \mathrm{~b}$ & $6,03 \mathrm{~b}$ & $3,81 \mathrm{~b}$ & $2,236 \mathrm{~b}$ & $3,13 \mathrm{~b}$ & $2,57 \mathrm{~b}$ & $4,23 \mathrm{a}$ & $8,03 \mathrm{~b}$ & $15,07 \mathrm{~b}$ \\
\hline BNT $5 \%$ & \multicolumn{3}{|c|}{1,03} & \multicolumn{3}{c|}{0,77} & \multicolumn{3}{c|}{0,88} \\
\hline
\end{tabular}

Keterangan (Remarks) : Nilai rata-rata yang diikuti huruf sama arah menurun tidak berbeda (Mean value followed by the same letter in vertical direction means not significance difference) 
Lampiran 3. Uji beda nyata $\left(\mathrm{BNT}_{0,05}\right)$ terhadap rata-rata penyusutan, pengembangan dan KAK bambu tali pada tingkat kekeringan yang berbeda

Appendix 3. Significant difference's range test $\left(B N T_{0,05}\right)$ to the average thickness shringkage, swelling and EMC of bambu tali on difference drying level

\begin{tabular}{|c|c|c|c|c|c|c|c|c|c|}
\hline \multirow{3}{*}{$\begin{array}{c}\text { Tingkat } \\
\text { kekeringan } \\
\text { (Drying } \\
\text { level), \%) }\end{array}$} & \multicolumn{9}{|c|}{ Rata-rata (Average) } \\
\hline & \multicolumn{3}{|c|}{$\begin{array}{c}\text { Penyusutan (Shrinkage), } \\
\% 0^{1}\end{array}$} & \multicolumn{3}{|c|}{$\begin{array}{c}\text { Pengembangan (Swelling), } \\
\% 0^{1}\end{array}$} & \multicolumn{3}{|c|}{ KAK (EMC.), \%1 } \\
\hline & $\mathrm{P}$ & $\mathrm{T}$ & $\mathrm{U}$ & $\mathrm{P}$ & $\mathrm{T}$ & $\mathrm{U}$ & $\mathrm{P}$ & $\mathrm{T}$ & $\mathrm{U}$ \\
\hline 0 & $13,33 a$ & $11,02 \mathrm{ab}$ & $9,50 \mathrm{~b}$ & $6,73 \mathrm{a}$ & $6,20 \mathrm{ab}$ & $5,73 \mathrm{~b}$ & $4,80 \mathrm{a}$ & $4,59 \mathrm{ab}$ & $4,37 b$ \\
\hline 6 & $9,60 \mathrm{a}$ & $7,73 b$ & $6,63 c$ & $9,53 \mathrm{a}$ & $9,17 \mathrm{ab}$ & $8,77 b$ & $9,02 \mathrm{a}$ & $8,87 \mathrm{ab}$ & $8,56 b$ \\
\hline 12 & $5,43 a$ & $4,63 \mathrm{ab}$ & $3,80 \mathrm{~b}$ & $16,39 a$ & $15,90 \mathrm{ab}$ & $15,57 b$ & $16,45 a$ & $16,22 \mathrm{a}$ & $16,20 \mathrm{a}$ \\
\hline $\mathrm{BNT}_{0,05}$ & \multicolumn{3}{|c|}{0,81} & \multicolumn{3}{|c|}{0,64} & \multicolumn{3}{|c|}{0,43} \\
\hline
\end{tabular}

Keterangan (Remarks) : ${ }^{1)}$ Nilai rata-rata yang diikuti oleh huruf kecil yang sama arah menurun tidak berbeda nyata (Mean value followed by the same letter in vertical direction means not significance difference); $\mathrm{P}=$ pangkal (bottom); $\mathrm{T}=$ tengah $($ middle); $\mathrm{U}=$ ujung (top)

Lampiran 4. Uji beda nyata $\left(\mathrm{BNT}_{0,05}\right)$ kombinasi umur dan tingkat kekeringan terhadap penyusutan, pengembangan dan KAK bambu tali

Appendix 4. Significant difference's range test $\left(B N T_{0,05}\right)$ of age and drying level combination to the average thickness shrinkage, swelling and EMC of bambutali

\begin{tabular}{|c|c|c|c|c|}
\hline \multirow{2}{*}{$\begin{array}{c}\text { Tingkat kekeringan } \\
\text { (Drying leveX, \% }\end{array}$} & \multirow{2}{*}{$\begin{array}{c}\text { Umur, tahun } \\
\text { (Age, year) }\end{array}$} & $\begin{array}{c}\text { Penyusutan } \\
\text { (Shrinkage) } \%\end{array}$ & $\begin{array}{c}\text { Pengembangan } \\
(\text { Swelling) } \%\end{array}$ & $\begin{array}{c}\text { KAK } \\
(\text { EMC.), } \%\end{array}$ \\
\cline { 3 - 5 } & 3 & $14,03 \mathrm{a}$ & $3,33 \mathrm{c}$ & $4,93 \mathrm{c}$ \\
& 4 & $10,83 \mathrm{~b}$ & $2,83 \mathrm{~d}$ & $4,83 \mathrm{c}$ \\
& 5 & $9,00 \mathrm{c}$ & $2,23 \mathrm{~d}$ & $4,00 \mathrm{~d}$ \\
\hline 6 & 3 & $10,03 \mathrm{c}$ & $4,20 \mathrm{~b}$ & $9,27 \mathrm{~b}$ \\
& 4 & $7,40 \mathrm{~d}$ & $3,53 \mathrm{c}$ & $8,70 \mathrm{c}$ \\
& 5 & $6,03 \mathrm{~d}$ & $3,13 \mathrm{c}$ & $8,53 \mathrm{c}$ \\
\hline 12 & 3 & $6,50 \mathrm{~d}$ & $5,13 \mathrm{a}$ & $16,67 \mathrm{a}$ \\
& 4 & $4,20 \mathrm{e}$ & $3,77 \mathrm{c}$ & $16,37 \mathrm{a}$ \\
& 5 & $3,17 \mathrm{e}$ & $2,57 \mathrm{~d}$ & $15,86 \mathrm{a}$ \\
\hline BNT 0,05 & & 1,42 & 0,98 & 1,22 \\
\hline
\end{tabular}

Keterangan (Remarks) : Nilai rata-rata yang diikuti oleh huruf kecil yang sama arah menurun tidak berbeda nyata (Mean value followed by the same letter in vertical direction means not significance difference) 